\title{
Nitric oxide synthase inhibitor improves de novo and long- term L-DOPA-induced dyskinesia in hemiparkinsonian rats
}

\section{Fernando Eduardo Padovan-Neto ${ }^{1,2}$, Marcela Bermúdez Echeverry ${ }^{2,3}$, Silvana Chiavegatto $^{4}$ and Elaine Del-Bel ${ }^{1,2 *}$}

\author{
' Department of Behavioral Neuroscience, Medical School, University of São Paulo, Ribeirão Preto, São Paulo, Brazil \\ 2 Department of Physiology, Dentistry School, University of São Paulo, Ribeirão Preto, São Paulo, Brazil \\ ${ }^{3}$ Department of Morphophysiology, School of Medicine, University of Santander, Campus Bucaramanga, Santander, Colombia \\ ${ }^{4}$ Department of Pharmacology, Biomedical Sciences Institute, University of São Paulo, Ribeirão Preto, SP, Brazil
}

\section{Edited by:}

Elizabeth Abercrombie, Rutgers-

Newark: The State University of New Jersey, USA

\section{Reviewed by:}

KueiY.Tseng, Rosalind Franklin University of Medicine and Science, USA

Jorge Aceves Ruíz, Centro de

Investigación y Estudios Avanzados del IPN, Mexico

\section{${ }^{*}$ Correspondence:}

Elaine Del-Bel, Departamento MEFFisiologia, Faculdade de Odontologia de Ribeirão Preto, Universidade de São Paulo, Av. Café S/N, Ribeirão Preto, SP 14040-904, Brazil.

e-mail: eadelbel@forp.usp.br
Inhibitors of neuronal and endothelial nitric oxide synthase decrease I-3,4-dihidroxifenilalanine (L-DOPA)-induced dyskinesias in rodents. The mechanism of nitric oxide inhibitor action is unknown. The aims of the present study were to investigate the decrease of L-DOPA-induced abnormal involuntary movements (AIMs) in 6-hydroxydopamine (6-OHDA)-lesioned rats by nitric oxide inhibitors following either acute or chronic treatment. The primary findings of this study were that NG-nitro-L-Arginine, an inhibitor of endothelial and neuronal nitric oxide synthase, attenuated AIMs induced by chronic and acute L-DOPA. In contrast, rotational behavior was attenuated only after chronic L-DOPA. The 6-OHDA lesion and the L-DOPA treatment induced a bilateral increase (1.5 times) in the neuronal nitric oxide synthase (nNOS) protein and nNOS mRNA in the striatum and in the frontal cortex. There was a parallel increase, bilaterally, of the FosB/ $\Delta$ FosB, primarily in the ipsilateral striatum. The exception was in the contralateral striatum and the ipsilateral frontal cortex, where chronic L-DOPA treatment induced an increase of approximately 10 times the nNOS mRNA. Our results provided further evidence of an anti-dyskinetic effect of NOS inhibitor. The effect appeared under L-DOPA acute and chronic treatment. The L-DOPA treatment also revealed an over-expression of the neuronal NOS in the frontal cortex and striatum. Our results corroborated findings that L-DOPA-induced rotation differs between acute and chronic treatment. The effect of the NOS inhibitor conceivably relied on the L-DOPA structural modifications in the Parkinsonian brain. Taken together, these data provided a rationale for further evaluation of NOS inhibitors in the treatment of L-DOPA-induced dyskinesia.

Keywords: nitric oxide, nitric oxide synthase, Parkinson's disease, L-DOPA-induced dyskinesia, nitric oxide synthase inhibitors, FosB/ $\Delta$ FosB, abnormal involuntary movements, striatum

\section{INTRODUCTION}

The impairments of Parkinson's disease (PD) can be controlled by treatment with the dopamine precursor $\mathrm{L}$-DOPA ( $\mathrm{L}-3,4$-dihydroxyphenylalanine). Regardless of treatment, the disease continues to progress (Tuite and Riss, 2003). Chronic treatment with L-DOPA causes abnormal involuntary movements (AIMs/dyskinesia) in both animals and humans (Marsden and Parkes, 1977; Iancu et al., 2005, for review see Jenner, 2008). The emergence of AIMs with repeated $\mathrm{L}$-DOPA treatment of 6-hydroxydopamine (6-OHDA) lesion rats has allowed for the examination of the mechanisms responsible for treatment-related dyskinesia in PD and the detection of molecules that are able to prevent or reverse their appearance (Cenci et al., 1998). Despite intensely investigated, long-term

Abbreviations: 6-OHDA, 6-hydroxidopamine; 7-NI, 7-nitroindazole; AIMs, abnormal involuntary movements; cGMP, cyclic guanosine monophosphate; eNOS, endothelial nitric oxide synthase; iNOS, inducible nitric oxide synthase; L-DOPA, L-3,4dihydroxyphenylalanine; L-NAME, N(G)-nitro-L-arginine methylester; L-NOARG, NG-nitro-L-Arginine; MFB, medial forebrain bundle; MPTP, 1-methyl-4-phenyl1,2,3,6-tetrahydropyridine; nNOS, neuronal nitric oxide synthase; NO, nitric oxide; NOS, nitric oxide synthase; PD, Parkinson's disease; sGC, soluble guanilyl cyclase; SIN-1, 3-morpholinosydonimine; SNc, substantia nigra pars compacta; SNL, lateral substantia nigra; $\mathrm{SNV}$, ventral substantia nigra; $\mathrm{TH}$, tyrosine hydroxylase. adaptations contributing to the development of $\mathrm{L}$-DOPA-induced dyskinesia, virtually nothing is known about the acute expression of dyskinetic movements after a single dose of $\mathrm{L}$-DOPA.

Parkinson's disease is also a disorder marked by an imbalance of non-dopaminergic transmitters (Jenner, 2008; Barone, 2010). Nitric oxide (NO) is a neurotransmitter formed from L-arginine and molecular oxygen by the action of three highly homologous isoforms of nitric oxide synthase (NOS): neuronal (nNOS), endothelial (eNOS), and inducible (iNOS; for review see Guix et al., 2005; Garthwaite, 2008). Within the striatum, endogenous NO is produced by a subclass of aspiny interneurons containing nNOS (Kubota et al., 1993; Morello et al., 1997; Kawaguchi, 1997; Tepper and Bolam, 2004) partly controlled by dopaminergic input (Kawaguchi, 1997; Calabresi et al., 2000; Centonze et al., 2001; West and Grace, 2002, 2004).

The production of $\mathrm{NO}$ and superoxide have been implicated in neurodegenerative disorders such as PD (Ebadi and Sharma, 2003). For example, in the striatum in Parkinsonian animal models and humans, NOS has been described as either depressed (rodents De-Vente et al., 2000; Barthwal et al., 2001; Sancesario et al., 2004; humans - Böckelmann et al., 1994; Eve et al., 1998) or increased (rodents - Ponzoni et al., 2000; Gomes and Del Bel, 2003; Gomes et al.,2008; humans-Hunot et al., 1996; Eve et al., 1998). Additionally, 
in the 6-OHDA-lesioned striatum, a considerable population of medium spiny neurons presented an excitatory response induced by the NO donor 3-morpholinosydonimine (SIN-1; Di Giovanni et al., 2003; Galati et al., 2008) instead of the inhibition observed in non-lesioned animals. Because NO may worsen PD symptoms (Gomes et al., 2008), several NOS inhibitors have been suggested for pharmacological treatment (Calabrese et al., 2000; Del-Bel et al., 2005; Aquilano et al., 2008; Jenner, 2008; Kavya et al., 2008).

Nitrergic mechanisms could contribute to L-DOPA-induced dyskinesia (Monville et al., 2006; Lane et al., 2008). In PD patients, L-DOPA therapy has been shown to cause a marked increase in the production of the NO second messenger cyclic guanosine monophosphate (cGMP) within the cerebellum and in the serum (Chalimoniuk et al., 2004). Sanchez et al. (2002) showed that NO stimulated ${ }_{\mathrm{L}}$-DOPA release in the striatum in a timeand concentration-dependent manner. In mice, ${ }_{\text {L-DOPA therapy }}$ has been shown to induce striatal NO production (Itokawa et al., 2006). Additionally, Chalimoniuk and Langfort (2007) showed

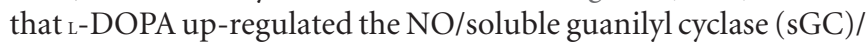
cGMP pathway to levels found in MPTP (1-methyl-4-phenyl1,2,3,6-tetrahydropyridine)-injected mice. Our group had recently shown that 7-nitroindazole (7-NI) and N(G)-nitro-L-Arginine (L-NOARG), nNOS and nNOS/eNOS inhibitors, respectively, can reduce the severity of $\mathrm{L}-\mathrm{DOPA}$-induced dyskinesia generated in the 6-OHDA-lesioned rats (Padovan-Neto et al., 2009; Novaretti et al., 2010) and mice (Del-Bel et al., 2011). Nevertheless, the mechanism of how NOS inhibition decreases L-DOPA-dyskinesias is unknown.

The aim of the present study was to investigate, in hemiparkinsonian rats, the effect of NOS inhibition in the $\mathrm{L}$-DOPA-induced AIMs achieved following either single or chronic treatment. The expression of the nNOS protein and mRNA was analyzed in the reactive 6-OHDA-lesioned and contralateral striatum.

\section{MATERIALS AND METHODS \\ DRUGS}

Apomorphine hydrochloride (Sigma-Aldrich, St. Louis, MO, USA); L-DOPA (Prolopa dispersive, Hoffman-LaRoche, Rio de Janeiro, RJ, Brazil) plus benserazide-HCl; NG-nitro-ı-arginine (L-NOARG; Sigma-Aldrich, St. Louis, MO, USA). All drugs were dissolved in physiological saline and administered in a volume of $2 \mathrm{ml} / \mathrm{kg}$.

\section{ANIMALS AND 6-HYDROXYDOPAMINE (6-OHDA) TREATMENT}

Adult male Wistar rats (200-250 g) were housed in groups of five per cage in a temperature-controlled room $\left(23^{\circ} \mathrm{C}\right)$, under 12 -h light/dark cycle with free access to food and water. Behavioral test was performed from 2:00 to 6:00 PM. All experiments were conducted according to the principles and procedures described by the Guidelines for the Care and Use of Mammals in Neuroscience and Behavioral Research (ILAR, USA). The Institution's housing conditions and experimental procedures were previously approved by the local Animal Ethics Committee (protocol number: 101/2009).

Rats were submitted to stereotaxic surgery as described by PadovanNeto et al. (2009). Briefly, rats were anesthetized with tribromoethanol (0.25 mg/kg i.p., Sigma-Aldrich, St. Louis, MO, USA) and received a single injection of either saline or 6-OHDA ( $16 \mu \mathrm{g}$ in $3 \mu \mathrm{l}$ of saline containing $0.05 \%$ ascorbic acid Sigma-Aldrich, St. Louis, MO, USA) into the right medial forebrain bundle (MFB), coordinates in mm relative to bregma: antero-posterior (AP):-4.4; lateral (L):-1.2; dorso-ventral (DV):-8.2 (Paxinos and Watson, 1998). The infusion was at the rate of $1 \mu \mathrm{l} / \mathrm{min}$ and the cannula was left in the place for $3 \mathrm{~min}$ before withdrawal. To limit the damage in noradrenergic neurons, desipramine hydrochloride (25 mg/kg i.p., Sigma-Aldrich, St. Louis, MO, USA) and pargyline ( $40 \mathrm{mg} / \mathrm{kg}$, Sigma-Aldrich, St. Louis, MO, USA) were administered 30 min before 6-OHDA injection. Brain was removed from the animals for western blot, RT-PCR and histopathological analyses. Two separate experimental groups of rats each were used for behavioral and pathological analyses. Behavioral experiments were performed on a separate group of animals.

\section{BEHAVIORAL TESTS \\ Stepping test}

This is a modified version of the stepping test originally proposed by Chang et al. (1999) and Olsson et al. (1995). Rats were held at the rear part of the torso by one hand with their hind limbs lifted and one forepaw held steady along its trunk by the hand of the experimenter. Then, the animal was moved ahead across a table for a distance of $90 \mathrm{~cm}$ in $12 \mathrm{~s}$ (Novaretti et al., 2010). During this interval the numbers of adjusting steps of the weight-bearing forepaw to compensate for the straight ahead movement of the body were counted. For each animal the test was begun randomly with the right or left forepaw. The animal performance was measures pre-drug, 1 and $2 \mathrm{~h}$ after L-DOPA intake (post-drug). The experimenter was blind to the treatment.

\section{Open field test}

The procedure was described by Cools (1980). The rats were placed in an open arena which consisted of a circular enclosure $(72 \mathrm{~cm}$ diameter) surrounded by a $49 \mathrm{~cm}$ Plexiglas wall with the floor divided into 12 sections. Rats were placed in the center of the arena and allowed to explore it for $5 \mathrm{~min}$. The following behaviors were recorded by observation: number of crossings (i.e., number of floor sections traversed, meaning horizontal exploration), the number of edge and center squares entered (Sullivan et al., 1994), the number of rearing (standing with the forepaws raised in the middle of the arena or against the walls, denoting the vertical exploration) and grooming.

\section{Rotational behavior test}

Rotational behavior was measured after either apomorphine or L-DOPA injection by placing the animals in a $40-\mathrm{cm}$-diameter bowl surrounded by a $16-\mathrm{cm}$ wall. The rats were allowed to acclimate to the environment for 5-10 min before drug treatment. Contralateral rotations, defined as complete $360^{\circ}$ turns away from the lesioned side of the brain, were counted. For apomorphine $(0.5 \mathrm{mg} / \mathrm{kg}$, s.c. $)$ the total number of full contralateral turns was counted during $45 \mathrm{~min}$. Only rats showing $>2$ turns $/ \mathrm{min}$ ( $>90$ turns $/ 45 \mathrm{~min}$ ) were included in the study. After $\mathrm{L}-\mathrm{DOPA}$ treatment (100 mg/kg, gavage), the number of contralateral turns was counted for $2 \mathrm{~h}$ in periods of $5 \mathrm{~min}$ at $0,25,55,85$, and $115 \mathrm{~min}$ after injection.

\section{Abnormal Involuntary Movements (AIMs)}

A trained observer blind to treatment assessed each rat for the presence of AIMs at 1 and $2 \mathrm{~h}$ after saline or L-DOPA accordingly to the rat dyskinesia scale (Cenci et al., 1998; Winkler et al., 2002). Briefly, rats were videotaped for $1 \mathrm{~min}$ and scores ranging from 0 to 
4 were given for topographical distribution of axial, limb, orofacial and locomotor AIMs. To obtain a more accurate scale, additional scores also ranging from 0 to 4 were attributed to the amplitude of axial and limb AIMs (Winkler et al., 2002). Each AIM was presented separately at 1 and $2 \mathrm{~h}$ after $\mathrm{L}-\mathrm{DOPA}$.

\section{TYROSINE HYDROXYLASE (TH) IMMUNORREACTIVITY}

Dopaminergic depletion was confirmed with immunohistochemistry.

\section{Tissue processing}

Twenty-four hours after last test, rats were deeply anesthetized with urethane (25 mg/kg, Sigma-Aldrich, St. Louis, MO, USA) and then rapidly perfused transcardiacally with $250 \mathrm{ml}$ of cold saline and $400 \mathrm{ml}$ of $4 \%$ paraformaldehyde (Sigma-Aldrich, St. Louis, MO, USA) in $0.1 \mathrm{M}$ phosphate buffer ( $\mathrm{pH}$ 7.4). The tissues were cut at $25 \mu \mathrm{m}$ on a freezing microtome. Sections through the striatum and SNc were collected in $0.01 \mathrm{M}$ phosphate-buffered saline solution containing $0.02 \%$ sodium azide and stored at $4^{\circ} \mathrm{C}$ until use.

\section{Immunohistochemistry reaction}

Tyrosine hydroxylase-immunohistochemistry was performed using a standard peroxidase based method (Gomes et al., 2008). Briefly, the sections were incubated with primary TH antibody (1:2000, Pel Freez, Rogers, AR, USA) overnight at $4^{\circ} \mathrm{C}$ followed by biotinylated secondary antibody (Vectastain ABC Kit, Vector Laboratories, Southfield, MI, USA) and horseradish peroxidase (HRP)-conjugated streptavidin (Vectastain ABC Kit, Vector Laboratories, Southfield, MI, USA). The sections were developed using diaminobenzidine (Sigma-Aldrich, St. Louis, MO, USA) as the chromogen.

\section{Image analysis}

The AP localizations (from Bregma in $\mathrm{mm}$ ) of the analyzed areas were: AP: -5.2 for SNc and AP: -6.03 for ventral and lateral substantia nigra (SNV and SNL respectively, Figure 1). Labeling of TH positive cells/fibers in SNc were assessed by measuring optical density of the entire area of the structure. Background (corpus callosum) was subtracted from all subsequent measurements. Results are presented the percentage of the optical density over the area (in $\mathrm{mm}^{2}$ ) of the ipsilateral side compared to the contralateral one. The number of TH positive neurons in the SNL and SNV were counted manually and results are expressed as the number of positive stained neurons per $\mathrm{mm}^{2}$ of the structure. For each selected area, quantifications were carried out using four sections per animal, separated by $125 \mu \mathrm{m}$ approximately. Quantifications were performed blindly, bilaterally, using a light microscope (Leica DMRB) equipped with a video camera (Leica DFC420). Neuroanatomical sites were identified using the atlas of Paxinos and Watson (1998). The analysis was done using the software Image ${ }^{1}$.

\section{WESTERN BLOT ANALYSIS}

The animals were decapitated, the lesion-reactive (right) and the contralateral (left-control) striatum were microdissected on an icecooled dissection cover, with the help of magnifying lens (Leica Zoom 2000), and immediately frozen in liquid nitrogen $\left(-196^{\circ} \mathrm{C}\right)$. Tissue samples were stored at $-80^{\circ} \mathrm{C}$ until use. Left and right striatum

${ }^{1}$ http://rsb.info.nih.gov was processed separately. The homogenates were centrifuged at $10000 \mathrm{rpm}$ for $25 \mathrm{~min}$ at $4^{\circ} \mathrm{C}$. The supernatants were recovered for protein concentration measurements using Bradford assay (Bio-Rad Protein assay, Bio-Rad, Germany). Proteins $(30 \mu \mathrm{g})$ were resolved by sodium dodecyl sulfate polyacrylamide gel electrophoresis $(8 \%$ SDS-PAGE) and semi-dry transferred to a nitrocellulose membrane.

Because the FosB primary antibody recognizes both full-length FosB and $\Delta$ FosB-related proteins, the staining obtained with this antibody is referred to as FosB/ $\Delta$ FosB. Nitrocellulose membranes were incubated at $4^{\circ} \mathrm{C}$ overnight using the following antibodies: mouse monoclonal anti-nNOS (1:1000, BD Biosciences, USA), rabbit polyclonal anti-FosB $/ \Delta$ FosB $(1: 1000$, Santa Cruz Biotechnology, USA), mouse monoclonal anti- $ß$-actin (1:5000, Santa Cruz Biotechnology, USA). Bound antibodies were detected with HRP-conjugated secondary anti-mouse or anti-rabbit antibodies (1:5000, Jackson Immuno Research Laboratories, USA). Bands were visualized by enhanced chemiluminescence (ECL, Amersham, UK) and quantified with the software Image ${ }^{2}$. The integrated density (product of the area and mean gray value) of each band of the proteins of interest was normalized to the integrated density of $B$-actin and used to compare relative levels of the proteins of interest. Each experiment was performed at least three times with similar results.

\section{REAL-TIME QUANTITATIVE PCR}

For RT-PCR (see Bibancos et al., 2007), the brain regions dissected were the prefrontal cortex, the striatum, and the hippocampus (contralateral and lesion-reactive), in a similar way described for the western blot. Frozen samples were immersed in TRIzol (Invitrogen ${ }^{\mathrm{TM}}$ Cat. No. 15596-026) and homogenized (Polytron PT10/35-Brinkmann, Westbury, NY, USA) by 30 s using maximum speed. Total RNA was isolated according to the manufacturer's guidelines and quantified by a spectrophotometer. The integrity of RNA was verified on ethidium bromide-stained 1\% agarose gel, and the fluorescence intensity ratio of 28S/18S rRNA was determined (Eagle Eye; Stratagene, La Jolla, CA, USA). Only samples that met our criteria of quality (both $260 / 280 \mathrm{~nm}$ and $28 \mathrm{~S} / 18 \mathrm{~S}>1.8$ ) were included in the experiments. The DNA was removed from RNA samples before reverse transcription with a RQ1 RNase-Free DNase (Promega Cat. No. M6101) at $37^{\circ} \mathrm{C}$ for $30 \mathrm{~min}$ and the enzyme inactivated at $65^{\circ} \mathrm{C}$ for $10 \mathrm{~min}$, maintaining the integrity of the RNA.

Total RNA $(2 \mu \mathrm{g})$ was reverse transcribed at the same time using a master mix containing oligo (dT; Invitrogen ${ }^{\mathrm{TM}}$ Cat. No. 18418-012) primer and SuperScript ${ }^{\mathrm{TM}}$ III Reverse Transcriptase (Invitrogen ${ }^{\mathrm{TM}}$ Cat. No. 18080-093) in a final volume of $20 \mu \mathrm{l}$. Specific primers (Rattusnorvegicus) for the nNOS enzyme, and the control genes cyclophilin A (peptidylprolylisomerase A: Ppia), glyceraldehyde3-phosphate dehydrogenase (Gapd) and beta-actin (Actb) were designed using the Primer 3 software ${ }^{3}$. The following criteria were followed: primer size (18-20 nucleotides), G/C content ( $~ 50 \%)$, annealing temperature $\left(58-60^{\circ} \mathrm{C}\right)$, amplicon size (93-221 nucleotides) and proximity of $3^{\prime}$ end, when possible. Forward and reverse primers were designed in different exons (with the exception of the intron less genes: Drd1a) and specificity was confirmed by a Basic

\footnotetext{
${ }^{2}$ http://rsb.info.nih.gov

${ }^{3}$ http://frodo.wi.mit.edu/cgi-bin/primer3/primer3_www.cgi

${ }^{4}$ http://www.ncbi.nlm.nih.gov/BLAST
} 
Local Alignment Search Tool (BLAST) ${ }^{4}$ software-assisted search of a non-redundant nucleotide sequence database for rat, and electrophoresis on an ethidium bromide-stained 3\% agarose gel. Real-time PCR analysis of gene expression was carried out in an ABI Prism 7700 sequence detection system (Applied Biosystems). The optimal concentration of cDNA and primers as well as the maximum efficiency of amplification were obtained through fivepoint, twofold dilution curve analysis for each gene. Each PCR contained $12.5 \mathrm{ng}$ of reverse-transcribed RNA, $200 \mathrm{~nm}$ of each specific primer, SYBR ${ }^{\oplus}$ GREEN PCR Master Mix (Applied Biosystems Cat. No. 4309155), and RNase free water to a $20 \mu$ final volume. cDNA samples from each area for all treatments and strain were processed at the same time in triplicate for each gene and the negative controls included for each brain area/primer. The PCR conditions were $10 \mathrm{~min}$ at $95^{\circ} \mathrm{C}$, followed by 40 cycles at $95^{\circ} \mathrm{C}$ for $15 \mathrm{~s}$ and $60^{\circ} \mathrm{C}$ for $60 \mathrm{~s}$, and a melting step (dissociation curve) was performed after each run to further confirm the specificity of the products and the absence of primer dimers. Real-time data were analyzed using Sequence Detector System 1.7 (Applied Biosystems). The relative expression in all brain areas was calculated according to a previous study (geNorm v 3.4, Vandesompele et al., 2002).

The following pairs of primers for cDNA, from genes available at the NCBI-NIH GeneBank, were used to nNOS (NM 052799; product of 202 bp): sense 5'-ATT CAA CAG CGT CTC CTC CT-3' and antisense $5^{\prime}$-AAT CCT CTC CCC TCC CAG T-3'. Reference genes: Ppia (NM 017101; product of $101 \mathrm{bp}$ ): sense 5'-AAT GCT GGA CCA AAC ACA AA- $3^{\prime}$ and antisense $5^{\prime}$-CCT TCT TTC ACC TTC CCA AA-3'; Gapd (NM 017008; product of 162 bp): sense 5'-ATG GTG AAG GTC GGT GTG-3' and antisense 5'-GAA CTT GCC GTG GGT AGA G-3'; Actb (NM 031144; product of 174 bp): sense 5'-CGT TGA CAT CCG TAA AGA CC-3' and antisense 5'-GCC ACC AAT CCA CAC AGA-3'.

\section{STATISTICAL ANALYSIS}

The effects of ${ }_{\mathrm{L}}-\mathrm{NOARG}$ on acute and chronic L-DOPA-induced AIMs were evaluated, respectively, by Mann-Whitney and Wilcoxon non-parametric tests. L-NOARG effects on rotational behavior were evaluated by one way repeated measure ANOVA (rANOVA), Student's $t$-test or Student's paired $t$-test as indicated. $\mathrm{L}$-NOARG effects on stepping test were obtained on each side (ipsi- and contralateral) with two way ANOVA or one way rANOVA as indicated. Stepping test was analyzed on each side by two way rANOVA being test session (pre-test and test) and time (day 1 and day 15) the repeated measures. When significant interactions were found on time, one way rANOVA were performed for each day. Western blot and data RT-PCR data was compared by using one and two way rANOVA as indicated. Data are presented as mean \pm SEM. Post $h o c$ analysis was performed by Sidak or Student $t$-test as indicated. Statistical significance level was set at $p<0.05$.

\section{EXPERIMENTAL DESIGN}

Unilaterally 6-OHDA-lesioned rats were assigned to treatment groups according to apomorphine-rotational behavior test performance (day 21 following surgery), to ensure that these measures were matched between groups. No ipsilateral rotation (complete $360^{\circ}$ turns toward the lesion-reactive striatum) was observed. 6-OHDA-lesioned rats presenting more than two rotations in 1 min were included in the study. .-DOPA or vehicle treatment started approximately 1 week after apomorphine test. The study consisted of four different experiments.

\section{Experiment 1}

Experiment 1 was a behavioral evaluation of control, 6-OHDA lesioned and dyskinetic rats to assess spontaneous locomotor activity, horizontal activity, and forelimb use asymmetry by the open field and the stepping tests. Approximately 2 days after the apomorphine-rotational behavior test (wash-out time), independent groups of 6-OHDA-lesioned $(n=7)$ and controls $(n=6-7)$ were submitted to the stepping test or the open field test. 6-OHDAlesioned rats treated with L-DOPA $(n=6-9)$ were also tested at the 15 th day of $\mathrm{L}$-DOPA treatment. The open field test was completed before $\mathrm{L}$-DOPA intake. The stepping test was performed before (pre-test) and after L-DOPA treatment.

\section{Experiment 2}

Experiment 2 aimed to compare the molecular effects in the striatum (bilaterally), estimating the nNOS expression (mRNA and protein) and FosB/ $\Delta$ FosB (protein). Rats were sacrificed $24 \mathrm{~h}$ after the last behavioral test for immunohistochemistry, western blot or RT-PCR analysis. The RT-PCR analysis was prepared in controls (control/saline, $n=7)$ and 6-OHDA-lesioned rats $(n=13)$. 6-OHDA-lesioned rats matched for the apomorphine-rotational behavior score were divided into two groups: 6-OHDA/sal (saline 15 days, once a day, gavage, $n=7$ ) and 6-OHDA/L-DOPA ( $\mathrm{-DOPA}+$ benserazide, 100 and $25 \mathrm{mg} / \mathrm{kg}$, respectively, 15 days, once a day, gavage, $n=6$ ). The western blot protein analysis was prepared in control/sal $(n=5), 6-\mathrm{OHDA} / \mathrm{sal}(n=5)$ and 6-OHDA/LDOPA + benserazide (100 and $25 \mathrm{mg} / \mathrm{kg}$ ) after either 1 day (acute; $n=5$ ) or 15 days (chronic; $n=5$ ) of treatment.

\section{Experiment 3}

Experiment 3 was designed to compare the behavioral effects of acute L-NOARG on established L-DOPA-induced AIMs. Rats received daily administration (for 15 days) of either vehicle (groups: control/sal, $n=10$ and 6-OHDA/sal, $n=10$ ) or L-DOPA + benserazide (groups: control/L-DOPA, $n=11$ and 6-OHDA/L-DOPA, $n=17$ ). Rats were matched for the AIM scores on day 15 of L-DOPA treatment. On day 16, animals were divided into subgroups: control/sal, $n=5$; 6-OHDA/sal, $n=5$; control/L-DOPA, $n=5-6$; or 6-OHDA/L-DOPA, $n=8-9$. Animals received (intraperitoneal (i.p.), $30 \mathrm{~min}$ before L-DOPA) either $50 \mathrm{mg} / \mathrm{kg}$ of ${ }_{\mathrm{L}}-\mathrm{NOARG}$ or saline. The ${ }_{\mathrm{L}}-\mathrm{NOARG}$ effect was calculated by comparing AIM scores, rotational behavior and the results of the stepping-test, between days 15 and 16 .

\section{Experiment 4}

Experiment 4 was designed to compare the behavioral effects of acute $_{\mathrm{L}}$-NOARG on acute $_{\mathrm{L}}$-DOPA-induced AIMs. Rats were divided into subgroups (control/sal, $n=5 ; 6-\mathrm{OHDA} / \mathrm{sal}, n=5-6$; control/ L-DOPA, $n=5$; or 6-OHDA/L-DOPA, $n=10-11$ ) and received either $50 \mathrm{mg} / \mathrm{kg}$ of ${ }_{\mathrm{L}}-\mathrm{NOARG}$ or saline $30 \mathrm{~min}$ before $\mathrm{L}-\mathrm{DOPA}$. AIMs, rotational behavior and the stepping test were evaluated.

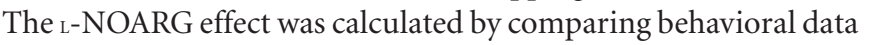
between the groups. 


\section{RESULTS}

6-OHDA-lesioned rats presented apomorphine-induced rotation contralateral to the lesion $(317 \pm 44$ turns $/ 45 \mathrm{~min})$. No rotation was observed in the control animals. Quantification of striatal TH-positive cells and fibers by optical density was measured in the substantia nigra compacta $(\mathrm{SNc})$ and in the SNL and SNV (Figure 1). TH-immunostaining (Figure 1A) indicated a dopaminergic cell loss $>95 \%$ in the SNc (Figure 1C), ipsilateral to the 6-OHDA injection (Figures 1A,B). SNL and SNV also presented a reduction in the number of cells and fibers (Figures 1A,B,D). No change was observed in control rats (data not shown).

\section{BEHAVIORAL EVALUATION OF 6-OHDA-INDUCED LESION AND L-DOPA- INDUCED AIMS IN RATS}

Due to the lack of statistical difference between tests performed at 1 and $2 \mathrm{~h}$ ( $p>0.05$, paired $t$-test) with the stepping test, data were presented as the mean of values collected at these times. 6-OHDAlesioned rats, but not controls, presented an impairment of the contralateral forehand paw when compared to the ipsilateral paw

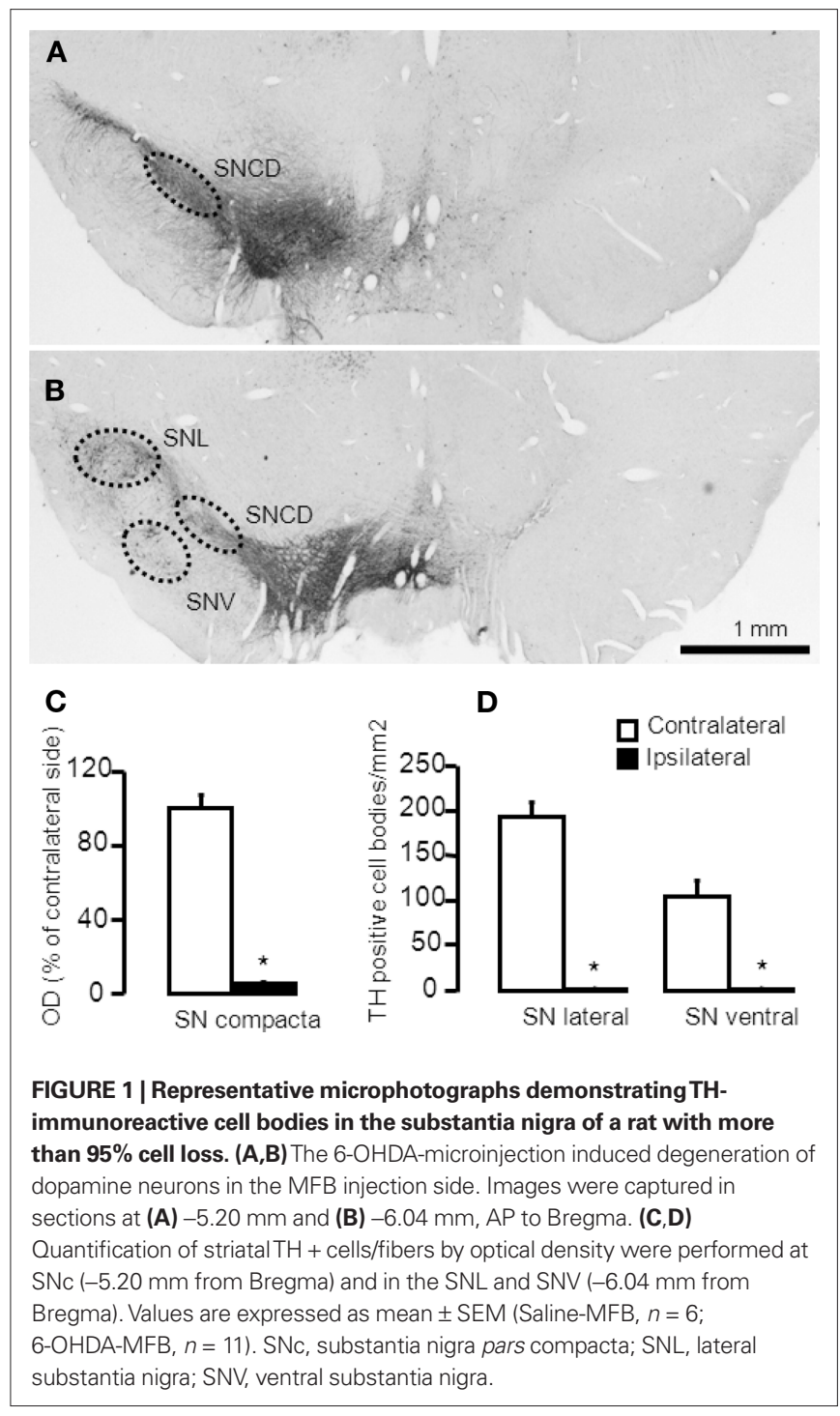

(approximately 70\%, Figure 2A). L-DOPA treatment on day 1 improved stepping performance (Figure 2B, group: $F_{(1,26)}=112.35$, $p<0.05$; test: $F_{(1,26)}=56.82, p<0.05$; interaction: $F_{(1,26)}=26.15$, $p<0.05)$. The effect was maintained through the last day of treatment (Figure 2B, day 15), with no differences between groups (pre-test and test, $p>0.05$ ). The ipsilateral paw adjusting steps were not changed by lesion or drug treatment (Figure 2A). Finally, there was a significant correlation ( $r=0.56, p=0.02$, Figure $2 \mathrm{C}$ ) between apomorphine induction of the rotational behavior and forehand paw test impairment.

The open field test revealed a decrease in the motor activity after 6-OHDA-lesion (rearing and the number of squares crossed in comparison with controls, Table 1; $p<0.05)$. The lesioned rats demonstrated a noticeable preference for exploration of the right side of the field, but there was no significant difference in grooming. L-DOPA treatment did not change these parameters $(p>0.05$; Table 1$)$.

\section{NEURONAL NOS EXPRESSION IN THE STRIATUM OF CONTROL, 6-OHDA-LESIONED AND L-DOPA-TREATED (DYSKINETIC) RATS}

In the striatum, the expression of nNOS transcript in both hemispheres differed significantly among the groups (Figure 3B; sidetreatment interaction: $\left.F_{(2,17)}=5.06, p<0.05\right)$. There was a modest increase (1.5 times) in the ipsilateral striatum of both 6-OHDAlesioned and dyskinetic rats. However, in the striatum contralateral to the lesion in the $\mathrm{L}$-DOPA-treated rats, there was a greater (10 times) increase in nNOS mRNA expression. A similar result was observed in the prefrontal cortex, but the greatest increase in nNOS mRNA was observed in the ipsilateral frontal cortex (Figure 3A; side-treatment interaction: $\left.F_{(2,16)}=14.91, p<0.05\right)$, Figure $3 \mathbf{A})$. No changes were observed in the hippocampus (Figure 3C, $p>0.05$ ).

The western blot analysis (Figure 4) indicated a bilateral increase in the nNOS protein content in the striatum (treatment: $F_{(2,6)}=82.56, p<0.05$, side: $F_{(1,6)}=17.22 ; p<0.05$; interaction: $\left.F_{(1,6)}=0.57 ; p<0.05\right)$. In the striatum of 6 -OHDA-lesioned and $\mathrm{L}$-DOPA-induced AIMs rats, there was an increase of nNOS protein between 19 and 24\% (Figure 4; $p<0.05$ ). Additionally, FosB $/ \Delta$ FosB protein was visualized bilaterally in the striatum of lesioned rats (Figure 5A). Acute and chronic L-DOPA administration to 6-OHDA-lesioned rats induced a bilateral increase in the expression of FosB $/ \Delta$ FosB protein (side: $F_{(1,4)}=757.77, p<0.05$; treatment: $F_{(1,4)}=314.46, p<0.05$; interaction: $F_{(1,4)}=201.30$, $p<0.05)$. The increase was larger in the striatum ipsilateral to the lesion. Chronic ${ }_{\mathrm{L}}$-DOPA treatment induced a more pronounced FosB $/ \Delta$ FosB expression in the ipsilateral striatum when compared to the ipsilateral striatum in the acute ${ }_{\mathrm{L}}$-DOPA-treated rats $(p<0.05$; Figure 5B).

\section{BEHAVIORAL EFFECTS OF ACUTE L-NOARG TREATMENT ON ESTABLISHED L-DOPA-INDUCED AIMS}

L-DOPA chronic treatment, in general, induced an increase in the number of turns (time: $F_{(2,32)}=78.27, p<0.05$ ) and AIMs $(p<0.05)$. L-DOPA treatment in the control rats induced no AIMs and no turns. L-NOARG reduced locomotor AIMs (Figure 6A, $1 \mathrm{~h} ; p<0.05$ ), limb/orofacial AIMs (Figure 6B; $2 \mathrm{~h} ; p<0.05$ ) and contralateral turns (Figures 6C,D; $p<0.05$ ). L-DOPA treatment 
A

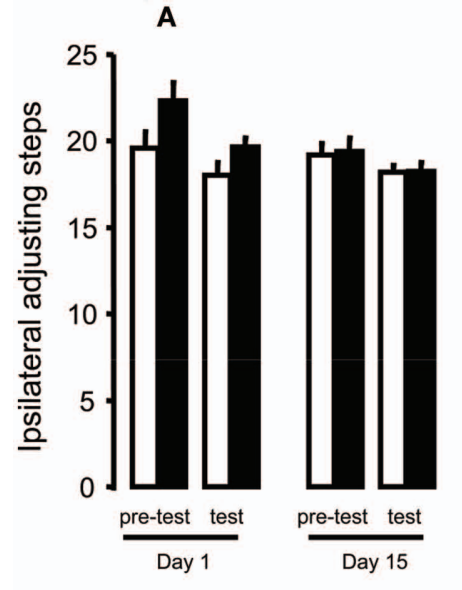

B

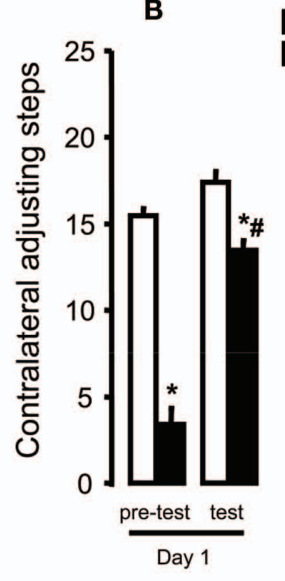

Saline-MFB

6-OHDA-MFB

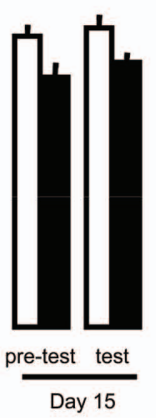

C

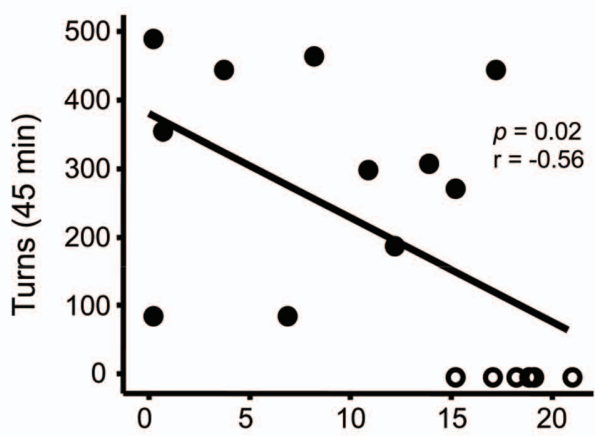

Number of adjusting steps
FIGURE 2 | Effects of 6-OHDA-lesion and L-DOPA treatment in the rodents stepping test. Rats received either saline $(n=17)$ or 6-OHDA $(n=11)$ microinjections on MFB. (A) For both groups, L-DOPA chronic treatment had no effect on the paw ipsilateral to the lesion. (B) 6-OHDA microinjection induced deficits in the paw contralateral to lesion (day 1 , pre-test) that was reversed by L-DOPA administration (day 1, test). L-DOPA treatment also improved the akinesia in the contralateral paw until the end of the treatment (day 15). (C) Spearman correlation between contralateral adjusting steps as a function of indirect striatal dopamine depletion provided by apomorphine-induced rotational behavior. ${ }^{*} p<0.05$ vs saline-FPM injected rats; $\# p<0.05$ vs pre-test (two way rANOVA). Values are expressed as mean \pm SEM.

Table 1 | Exploratory behavior of rats in open field arena.

\begin{tabular}{|c|c|c|c|c|}
\hline & Rearings & Squares crossed & Grooming & Preference ( $\%)$ \\
\hline Control $(n=7)$ & $26 \pm 2.58$ & $31.29 \pm 2.81$ & $5 \pm 0.62$ & Left: 100 \\
\hline \multirow[t]{2}{*}{$6-\mathrm{OHDA}(n=7)$} & $15.14 \pm 3.82^{*}$ & $17.43 \pm 2.22^{*}$ & $4.29 \pm 1.02$ & Right: 85.7 \\
\hline & & & & Left: 14.3 \\
\hline \multirow[t]{2}{*}{ 6-OHDA/L-DOPA $(n=6) /$ day 1} & $10 \pm 2.50$ & $14.83 \pm 1.89$ & $3 \pm 0.58$ & Right: 83.3 \\
\hline & & & & Left:16.6 \\
\hline 6-OHDA/L-DOPA $(n=6) /$ day 15 & $5.83 \pm 1.74$ & $10.33 \pm 1.38$ & $2.67 \pm 0.56$ & Right: 100 \\
\hline
\end{tabular}

Numbers are mean \pm SEM. ${ }^{*} p<0.05$ vs control (paired t-test).

improved stepping test performance in the contralateral paw, as demonstrated in Figure 2. The adjusting step in the ipsilateral paw

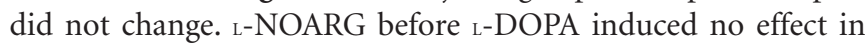
the ipsilateral paw (Figure 6E; $p>0.05$ ) but did result in a small reduction $(<20 \%)$ in the contralateral paw (Figure 6F; treatment: $F_{(1,11)}=3.02, p>0.05$; group: $F_{(1,11)}=1.57, p>0.05$; interaction: $\left.F_{(1,11)}=9.01, p<0.05\right)$.

\section{BEHAVIORAL EFFECTS OF L-NOARG ON ACUTE L-DOPA-INDUCED AIMS}

All subtypes of AIMs were observed 1 and $2 \mathrm{~h}$ after the administration of acute L-DOPA to 6-OHDA-lesioned rats (Figures 7A,B). Pre-treatment with $\mathrm{L}-\mathrm{NOARG}$ reduced AIMs (limb, limb amplitude, and orofacial) at the first hour (Figures 7A,B, $p<0.05$ ) and loco-

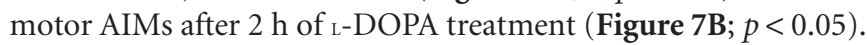
In contrast, $\mathrm{L}-\mathrm{NOARG}$ did not change ${ }_{\mathrm{L}}$-DOPA-induced rotation (Figures 7C,D). Administration of a single ${ }_{\mathrm{L}}$-DOPA treatment to 6-OHDA-lesioned rats induced a slight increase in the stepping test performance of the ipsilateral paw, with no difference in the contralateral paw (Figure 7E; group: $F_{(1,27)}=0.38, p>0.05$; treatment: $F_{(1,27)}=2.26, p>0.05$; interaction: $\left.F_{(1,27)}=6.94, p<0.05\right)$.
Pre-treatment with L-NOARG decreased stepping test in the contralateral paw performance (Figure 7F; group, $F_{(1,27)}=16.23$, $p<0.05$; treatment: $F_{(1,27)}=5.21, p<0.05$; interaction: $F_{(1,27)}=11.37$, $p<0.05)$ with no effect in the ipsilateral paw.

\section{DISCUSSION}

The main findings of this study were that $\mathrm{L}-\mathrm{NOARG}$ attenuated AIMs induced by acute and chronic ${ }_{L}$-DOPA treatment. Rotational behavior was attenuated only after chronic L-DOPA administration. L-DOPA improved stepping test performance, and its chronic administration did not alter open field behavior. Our results indicated a correlation between apomorphine-induced rotation and the decrease in the number of adjusting steps performed with the contralateral forepaw in the 6-OHDA-lesioned rats. In the striatum and the frontal cortex, the 6-OHDA lesion and the L-DOPA treatment induced a bilateral increase in the $\mathrm{nNOS}$ protein, $\mathrm{nNOS}$ mRNA and the FosB $/ \Delta$ FosB, the FosB $/ \Delta$ FosB being greatest in the ipsilateral striatum. In contrast, there was an increase of 10 times in the nNOS mRNA in the contralateral striatum and in the ipsilateral frontal cortex with L-DOPA-chronic treatment. 


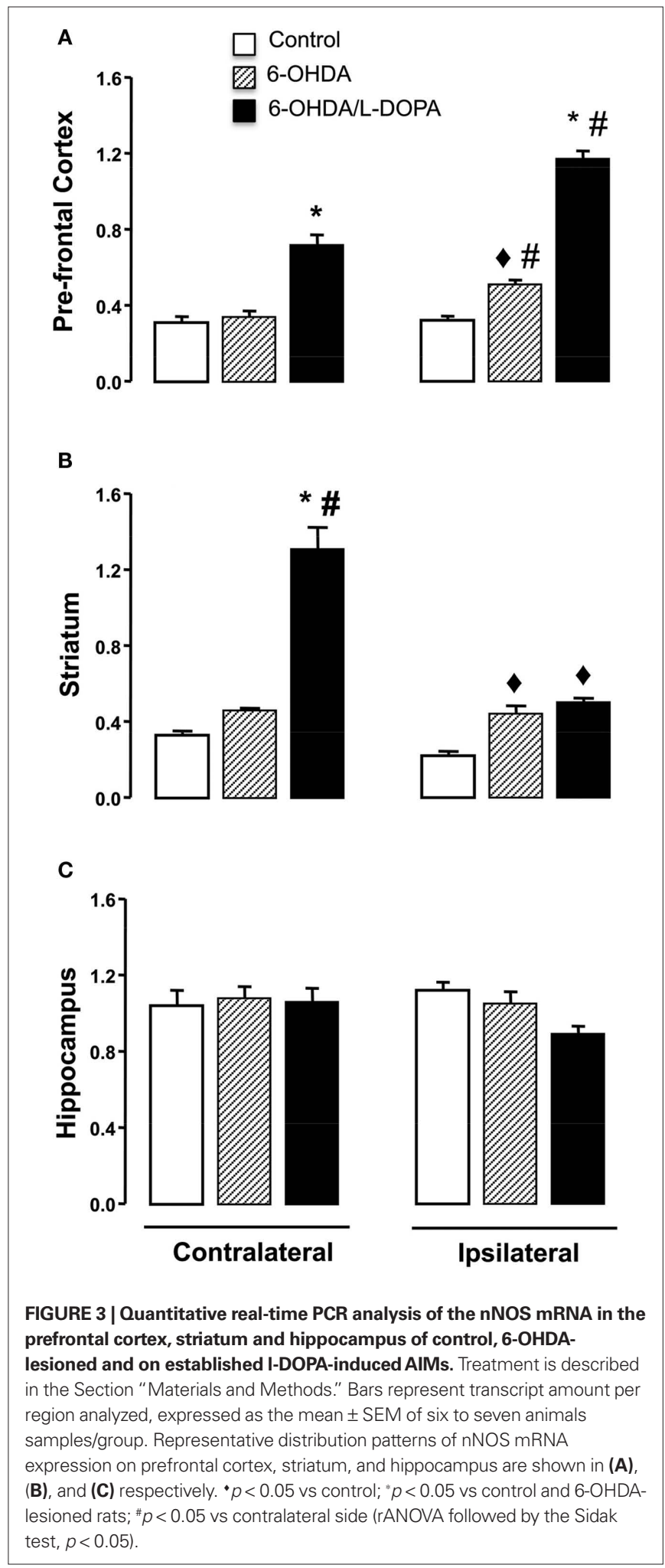

Individual AIM categories are highly interrelated, but this does not imply that each AIM category represents the same phenomena. Moreover, there is currently no consensus on the

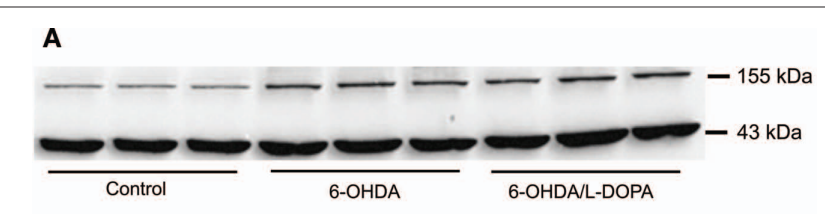

в

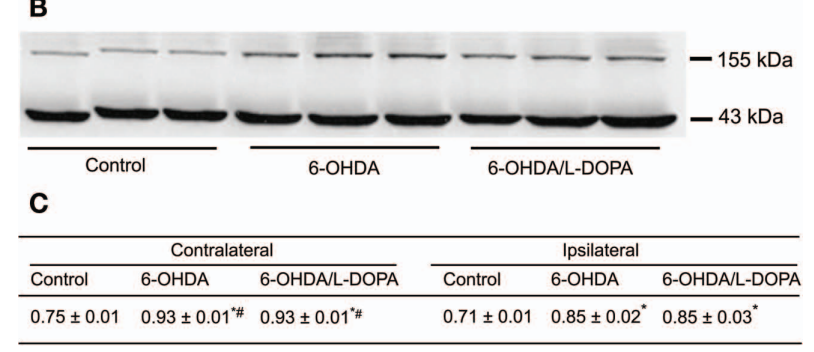

FIGURE 4 |Western blot analysis of nNOS protein in the rat striatum: effect of lesion and L-DOPA chronic treatment in control, 6-OHDA-lesioned and on established L-DOPA-induced AIMs. Treatment is described in Methods. (A) Contralateral and, (B) ipsilateral striatum. Lines indicate specific bands at $\sim 155 \mathrm{kDa}$ (nNOS) and $\sim 43 \mathrm{kDa}$ of a loading control ( $\beta$-actin). (C) There was an increment of nNOS protein expression in both ipsilateral and contrataleral striatum for 6-OHDA-lesioned and L-DOPA-treated-6-OHDA-lesioned rats. The values obtained from contralateral side were higher than the ipsilateral one. * $p<0.05$ vs control; ${ }^{*} p<0.05$ vs ipsilateral side (rANOVA followed by the Sidak test, $p<0.05$ ).

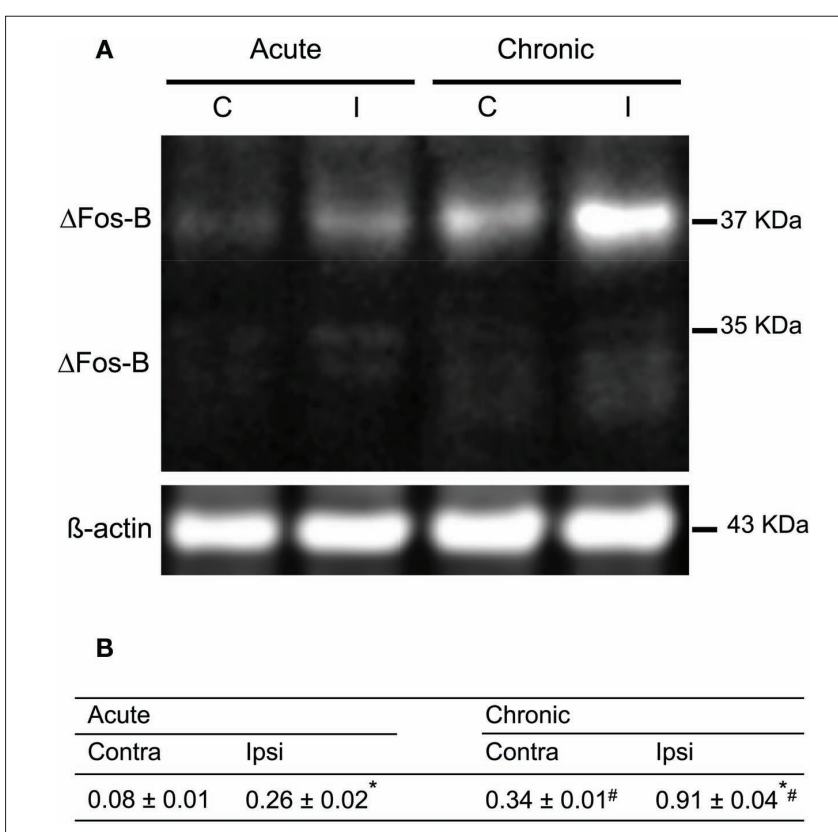

FIGURE 5 | Characterization of the expression of FosB/ $\Delta$ Fos B after acute and on established L-DOPA-induced AIMs. (A) Western blots of proteins from extracted striatum of acutely and chronically L-DOPA-treated hemiparkinsonian rats; left and right lanes represent proteins from ipsilateral (I) and contralateral (C) striatum, respectively. (B) Results of the quantification of L-DOPA-induced FosB/ $\Delta$ FosB expression are expressed as the integrated density of each band of the proteins of interest was normalized to the integrated density of the control loading ß-actin (mean \pm SEM; square pixel). ${ }^{*} p<0.05$ compared with contralateral striatum for either acute or chronic treatment with L-DOPA (paired $t$-test). ${ }^{\prime} p<0.05$ compared with the same side for acute or chronic treatment with L-DOPA ( $t$-test). 
A

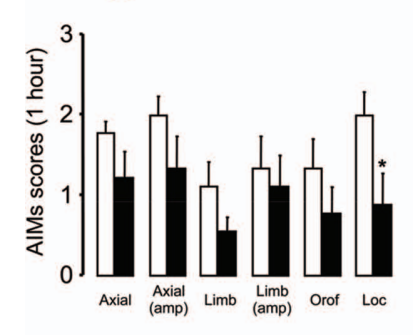

B

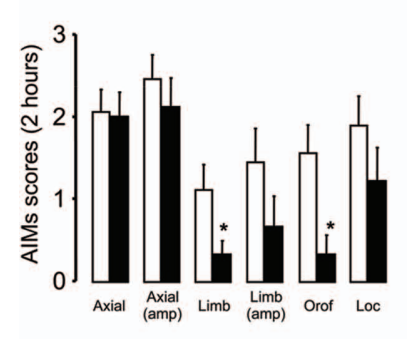

C

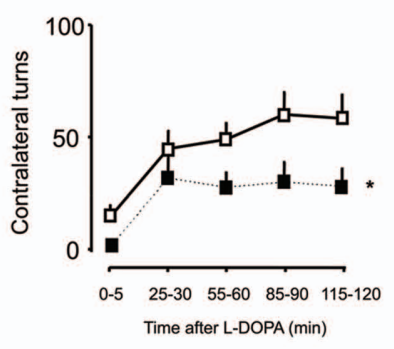

D

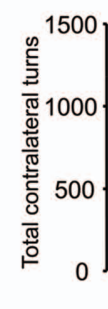

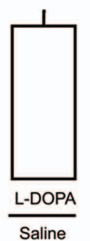

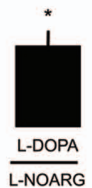

E

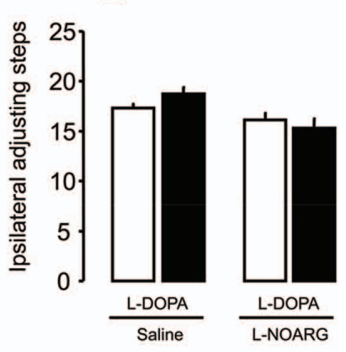

$\mathbf{F}$

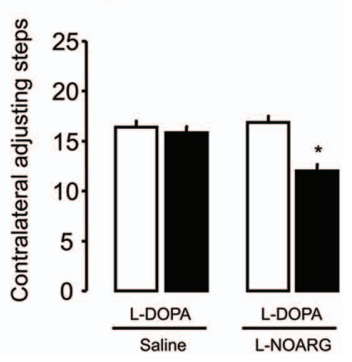

FIGURE 6 | Effects of L-NOARG pre-treatment on AIMs, rotational behavior and stepping test on established L-DOPA-induced AIMs. (A) L-NOARG pre-treatment significantly reduced locomotor AIM scores at $1 \mathrm{~h}$ after L-DOPA. (B) Limb and orofacial AIMs scores were significantly reduced by L-NOARG at $2 \mathrm{~h}$ after L-DOPA. * $p<0.05$ (Wilcoxon). (C) L-NOARG pre-treatment reduced contralateral turns measured during 5 min at 0, 25, 55, 85, and 115 min after L-DOPA treatment.
${ }^{*} p<0.05$ (one way rANOVA). (D) L-NOARG reduced total contralateral turns measured during $120 \mathrm{~min}$ after L-DOPA. $p<0.05$ (paired t-test). After chronic L-DOPA treatment L-NOARG pre-treatment did not affect (E) ipsilateral adjusting steps and (F) slight reduced adjusting steps performed with contralateral paw. ${ }^{*} p<0.05$ vs Saline-FPM (one way rANOVA). Values are expressed as mean \pm SEM (6-OHDA-FPM, $n=8-9 /$ group; Saline-FPM, $n=5$-6/group). behavioral components underlying turning. The interpretation of circling behavior has been greatly debated with the introduction of a rodent rating scale for dyskinesia (Henry et al., 1998; Lundblad et al., 2002; Konitsiotis and Tsironis, 2006; Lane et al., 2006; Cenci and Konradi, 2010). The phenomenon of rotation was first described by Ungerstedt and Arbuthnott (1970). The administration of post-synaptic dopamine agonists, such as L-DOPA, induced contraversive rotation through asymmetric striatal receptor stimulation (Zetterstrom et al., 1986; Schwarting et al., 1991). The mechanisms by which asymmetry in central dopaminergic systems translated into the motor response of turning remains unclear (for a review, see Miller and Beninger, 1991; Dunnett and Robbins, 1992). Turning has been interpreted as either a lateralized expression of sensory hyperattention or as the result of asymmetries in the dopaminergic control of posture or locomotion (for review see Miller and Beninger, 1991; Schwarting and Huston, 1996; Lundblad et al., 2002). Early reports suggested that the amplitude enhancement of the contralateral rotational response was caused by basal ganglia sensitization similar to that thought to underlie the development of dyskinesias (Papa et al., 1994; Henry et al., 1998; Mura et al., 2002). Our results corroborated findings of L-DOPA-induced rotation differences between acute and chronic treatment. It reflected a difference in the underlying neural mechanisms revealed by the distinct NO system interference.

The adjusting steps task is used as an index of severe dopaminergic depletion (Olsson et al., 1995; Schwarting and Huston, 1996; Chang et al., 1999). In corroboration, adjusting steps correlated with apomorphine-induced rotations. L-NOARG per se slightly decreased adjusting steps of the contralateral paw, an effect that disappeared with chronic ${ }_{\mathrm{L}}$-DOPA treatment. The impairment in the stepping test could be interpreted as motor behavior impairment in the unprimed $\mathrm{L}_{\mathrm{-}} \mathrm{DOPA}$ rats. However, previous results (Novaretti et al., 2010) have shown no interference of 7-NI in the stepping test performance following either acute or chronic $\mathrm{L}$-DOPA treatment. The open field test, a test that evaluates exploratory behavior as an index of motor activity, was not modified by either acute or

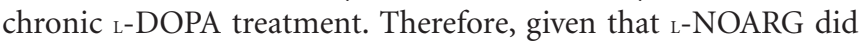
not interfere with acute $\mathrm{L}$-DOPA rotational behavior, our results suggested that the effect of the NOS inhibitor could conceivably rely on the L-DOPA structural modifications in the Parkinsonian brain (Cenci et al., 1998, 2002; Lundblad et al., 2002).

The implications of $\mathrm{NO}$ in the response to anti-dyskinetic therapy are poorly understood. Substantial evidence has demonstrated the involvement of NO in the degeneration of dopaminergic neurons of the nigrostriatal pathway (Duncan and Heales, 2005). There are several possible mechanisms through which NOS inhibitors may influence L-DOPA-induced dyskinesias. NO modulates L-DOPA release from the striatum (Sanchez et al., 2002; AbreuGonzález et al., 2006). Additionally, in the rat striatum and medial preoptic area, NO increased both dopamine and serotonin release in a cGMP-dependent manner (Trabace et al., 2004). The development of abnormal movements has been associated with changes in gene and protein expression in dopamine-denervated striatal neurons (Cenci et al., 1998; Andersson et al., 1999; Pavón et al., 2006). In response to $\mathrm{L}-\mathrm{DOP} A, \mathrm{Fos} B / \Delta$ FosB expression appeared to be selectively induced in the nitrergic neurons in the striatum, 
A
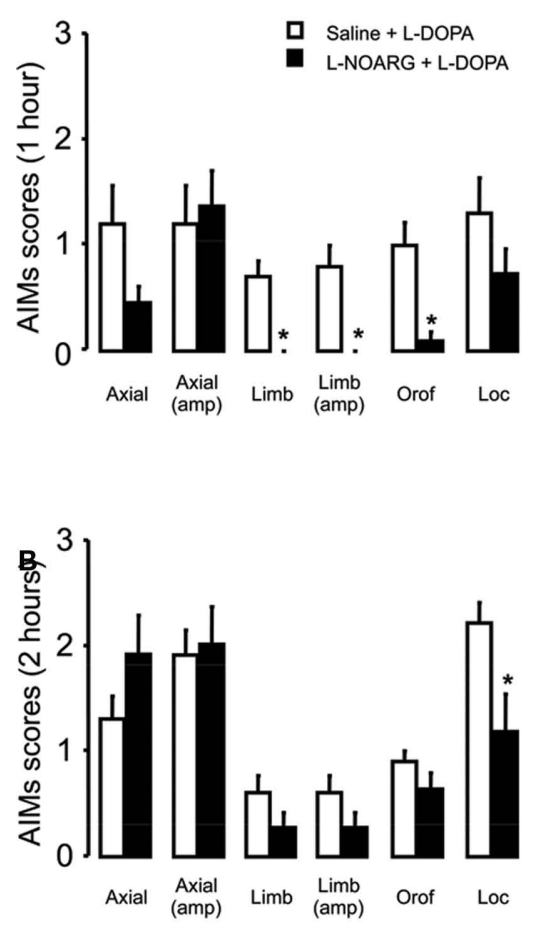

C

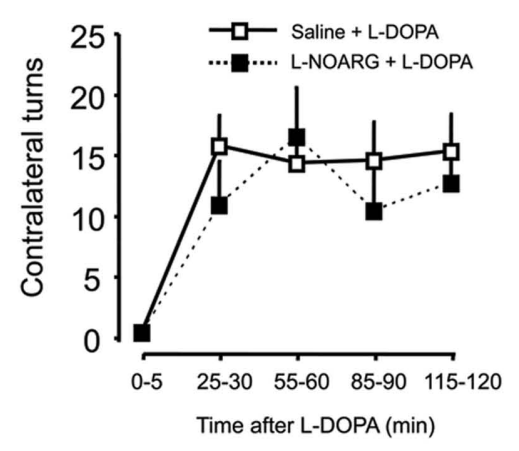

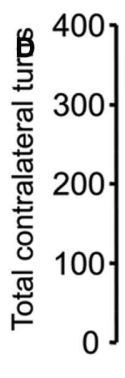

E
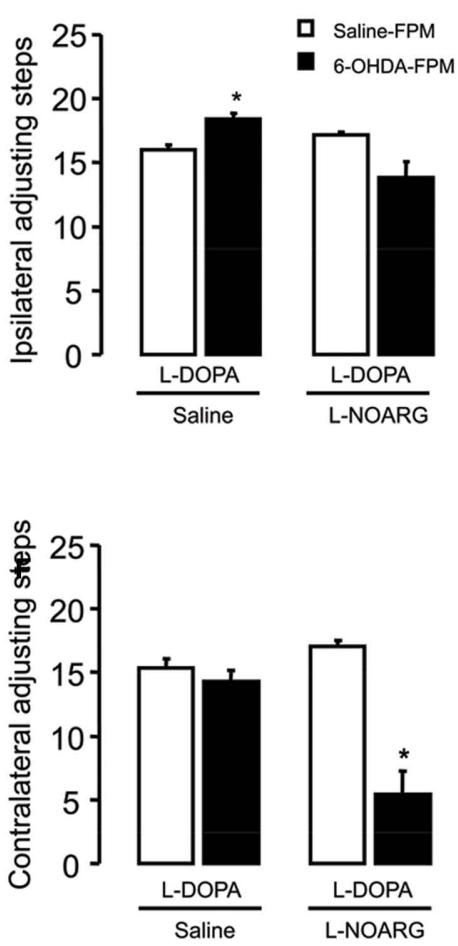

FIGURE 7 | Effects of L-NOARG pre-treatment on AIMs, rotational behavior and stepping test on acute L-DOPA-induced AIMs. (A) L-NOARG pre-treatment significantly reduced limb, limb amplitude and orofacial AIMs scores $1 \mathrm{~h}$ after L-DOPA application. (B) Locomotor AIM score was attenuated by L-NOARG $2 \mathrm{~h}$ after L-DOPA treatment. * $p<0.05$ (Mann-Whitney). (C) L-NOARG pre-treatment had no effects on contralateral turns measured during 5 min at $0,25,55,85$, and 115 min after L-DOPA treatment $p>0.05$ (two way rANOVA) neither on (D) total contralateral turns, assessed during 120 min after L-DOPA treatment. $p>0.05$ (t-test) (E) L-DOPA treatment slightly increased the number of the adjusting steps of 6-OHDA-lesioned rats in the paw ipsilateral to the lesion. (F) L-DOPA treatment completely restored the akinesia in the contralateral-to lesion paw, of 6-OHDAlesioned rats but L-NOARG pre-treatment impaired L-DOPA effect. ${ }^{*} p<0.05$ vs Saline-FPM injected (two way ANOVA). Values are expressed as mean \pm SEM (6-OHDA-FPM, $n=10-11$ /group; Saline-FPM, $n=5$ /group). where it facilitates the expression of histone acetyltransferase, resulting in enhanced local phosphorylated histone and further changes in gene expression (Darmopil et al., 2009; Santini et al., 2009). NO may be involved either in the neurodegeneration/death or neuroprotection of dopaminergic neurons (Przedborski et al., 1996; Dehmer et al., 2000; Zhang et al., 2000; Gomes and Del-Bel, 2003; Gomes et al., 2008).

L-DOPA-induced dyskinesia has been linked to pathological cortico-striatal synaptic plasticity, which is mediated by long-lasting molecular changes (for review see Cenci and Konradi, 2010). In $\mathrm{PD}$, there is an increase in NADPH-diaphorase-positive glial cells in the substantia nigra suggesting up-regulation of iNOS (Hunot et al., 1996), but there is also elevated expression of nNOS mRNA in other areas of basal ganglia (Eve et al., 1998) and increased nitrite levels in the cerebrospinal fluid (Qureshi et al., 1995), all suggesting increased NO production. Nevertheless, De-Vente et al. (2000) and Sancesario et al. (2004) reported that lesions of the dopaminergic innervation also using 6-OHDA resulted in a 50\% decrease in NOS activity in the injured striatum and frontal cortex. We could not explain why NOS mRNA was increased 10 times (approximately) in the contralateral striatum and frontal cortex and why it did not result in protein increase. It is possible that nNOS expression increase is associated with neurodegenerative rearrangements of the remaining neurocircuitries, preserving and/or further impairing the affected functions.

\section{CONCLUSION}

Our study provided further evidence of the anti-dyskinetic effects of a NOS inhibitor under acute and chronic L-DOPA treatment. Our results revealed an over-expression of the neuronal NOS in the frontal cortex and striatum in Parkinsonian and dyskinetic rats probably associated with rearrangements of the remaining neurocircuitries,. Taken together, these data provide a rationale for further evaluation of NOS inhibitors in the treatment of $\mathrm{L}_{\mathrm{L}}$ DOPA-induced dyskinesia.

\section{ACKNOWLEDGMENTS}

This research was supported by grants from CAPES/COFECUB, FAPESP/INSERM, FAPESP, and CNPq. We would like to acknowledge the Célia A. da-Silva excellent technical assistance. This work would not be realized without the assistance and kindness of Professor José Eduardo Krieger - INCOR-USP. 


\section{REFERENCES}

Abreu-González, P., González-Hernández, T.,Afonso-Oramas, D., Cruz-Muros, I. Barroso-Chinea, P., González, M., and C. (2006). Tetrahydrobiopterin stimulates L-DOPA release from striatal tissue. Eur. J. Pharmacol. 541, 33-37.

Andersson, M., Hilbertson, A., and Cenci, M.A. (1999). Striatal fosB expression is causally linked with 1-DOPA-induced abnormal involuntary movements and the associated upregulation of striatal prodynorphin mRNA in a rat model of Parkinson's disease. Neurobiol. Dis. 6, 461-474.

Aquilano, K. Baldelli S. Rotilio G, and CirioloMR. (2008). Role of nitric oxide synthases in Parkinson's disease: a review on the antioxidant and anti-inflammatory activity of polyphenols. Neurochem. Res. 33, 2416-2426.

Barone, P. (2010). Neurotransmission in Parkinson's disease: beyond dopamine. Eur. J. Neurol. 17, 364-376.

Barthwal, M. K., Srivastava, N., and Dikshit, M. (2001).Role of nitric oxide in a progressive neurodegeneration model of Parkinson's disease in the rat. Redox Rep. 6, 297-302.

Bibancos, T., Jardim, D. L., Aneas, I., and Chiavegatto, S. (2007). Social isolation and expression of serotonergic neurotransmission-related genes in several brain areas of male mice. Genes Brain Behav. 6, 529-539.

Böckelmann, R., Wolf, G., Ransmayr, G., and Riederer, P. (1994). NADPHdiaphorase/nitric oxide synthase containing neurons in normal and Parkinson's disease putamen. J. Neural Transm. Park. Dis. Dement. Sect. 7, 115-121.

Calabrese, V., Bates, T. E., and Stella, A. M. (2000). NO synthase and NO-dependent signal pathways in brain aging and neurodegenerative disorders: the role of oxidant/antioxidant balance. Neurochem. Res. 25, 1315-1341.

Calabresi, P., Centonze, D., Gubellini, P., Marfia, G. A., Pisani, A., Sancesario, G., and Bernardi, G. (2000). Synaptic transmission in the striatum: from plasticity to neurodegeneration. Prog. Neurobiol. 61, 231-265.

Cenci, M. A., and Konradi, C. (2010). Maladaptive striatal plasticity in L-DOPA-induced dyskinesia. Prog. Brain Res. 183, 209-233.

Cenci, M. A., Lee, C. S., and Bjorklund, A. (1998). L-DOPA-induced dyskinesia in the rat is associated with striatal overexpression of prodynorphin- and glutamic acid decarboxylase mRNA. Eur. J. Neurosci. 10, 2694-2706.

Cenci, M. A., Whishaw, I. Q., and Schallert, T. (2002). Animal models of neurological deficits: how relevant is the rat? Nat. Rev. Neurosci. 3, 574-579.

Centonze, D., Picconi, B., Gubellini, P., Bernardi, G., and Calabresi, P. (2001). Dopaminergic control of synaptic plasticity in the dorsal striatum. Eur. J. Neurosci. 13, 1071-1077.

Chalimoniuk, M., and Langfort, J. (2007). The effect of subchronic, intermittent L-DOPA treatment on neuronal nitric oxide synthase and soluble guanylylcyclase expression and activity in the striatum and midbrain of normal and MPTP-treated mice. Neurochem. Int. 50, 821-833.

Chalimoniuk, M., Stepie, A., and Strosznajder, J. B. (2004). Pergolidemesylate, a dopaminergic receptor agonist, applied with L-DOPA enhances serum antioxidant enzyme activity in Parkinson disease. Clin. Neuropharmacol. 27, 223-229.

Chang, J.W., Wachtel, S. R., Young, D., and Kang, U. J. (1999). Biochemical and anatomical characterization of forepaw adjusting steps in rat models of Parkinson's disease: studies on medial forebrain bundle and striatal lesions. Neuroscience 88, 617-628.

Cools, A. R. (1980). Role of the neostriatal dopaminergic activity in sequencing and selecting behavioural strategies: facilitation of processes involved in selecting the best strategy in a stressful situation. Behav. Brain Res. 1,361-378.

Darmopil, S., Martín, A. B., De Diego, I R., Ares, S., and Moratalla, R. (2009) Genetic inactivation of dopamine D1 but not D2 receptors inhibits LDOPAinduced dyskinesia and histone activation. Biol. Psychiatry 66, 603-613.

Dehmer, T., Lindenau, J., Haid, S., Dichgans, J., and Schulz, J. B. (2000). Deficiency of inducible nitric oxide synthase protects against MPTP toxicity in vivo. J. Neurochem. 74, 2213-2216.

Del-Bel, E., Padovan-Neto, F.E., RaismanVozari, R., and Lazzarini, M. (2011). Role of nitric oxide in motor control: implications for Parkinson's disease pathophysiology and treatment. Curr. Pharm. Des. 17, 471-488.

Del-Bel,E.A., Guimarães, F. S., BermudezEcheverry, M., Gomes, M. Z., Schiaveto-De-Souza, A., PadovanNeto, F., Tumas, V., Barion-Cavalcanti, A. P., Lazzarini, M., Nucci-Da-Silva, L. P., and De Paula-Souza, D. (2005). Role of nitric oxide on motor behavior. Cell. Mol. Neurobiol. 25, 371-392.

De-Vente, J., Van Ittersum, M., Van Abeelen, J., Emson, P. C., Axer, H., and Steinbusch, H. W. M. (2000). NO-mediated cGMP synthesis in cholinergic neurons in the rat forebrain: effects of lesioning dopaminergic or serotonergic pathways on $\mathrm{nNOS}$ and
cGMP synthesis. Eur. J. Neurosci. 12 507-519.

Di Giovanni, G., Ferraro, G., Sardo, P., Galati, S., Esposito, E., and La Grutta, V. (2003). Nitric oxide modulates striatal neuronal activity via soluble guanylylcyclase: an in vivo microiontophoretic study in rats. Synapse 48 100-107.

Duncan, A. J., and Heales, S. J. (2005) Nitric oxide and neurological disorders. Mol. Aspects Med. 26, 67-96.

Dunnett, S. B., and Robbins, T.W. (1992). The functional role of mesotelencephalic dopamine systems. Biol. Rev. Camb. Philos. Soc. 67, 491-518.

Ebadi, M., and Sharma, S. K. (2003). Peroxynitrite and mitochondrial dysfunction in the pathogenesis of Parkinson's disease. Antioxid. Redox Signal. 5, 319-335.

Eve, D., Nisbet, A., Kingsbury, A., Hewson, E., Daniel, S., Lees, A., Marsden, C., and Foster, O. (1998). Basal ganglia neuronal nitric oxide synthase mRNA expression in Parkinson's disease. Brain Res. Mol. Brain Res. 63, 62-71.

Galati, S., D’Angelo, V., Scarnati, E., Stanzione, P., Martorana, A., Procopio, T., Sancesario, G., and Stefani, A (2008). In vivo electrophysiology of dopamine-denervated striatum: focus on the nitric oxide/cGMP signaling pathway. Synapse 62, 409-420.

Garthwaite, J. (2008). Concepts of neural nitric oxide-mediated transmission. Eur. J. Neurosci. 27, 2783-2802.

Gomes, M. Z., and Del Bel, E. A. (2003). Effects of electrolytic and 6-hydroxydopamine lesions of rat nigrostriatal pathway on nitric oxide synthase and nicotinamide adenine dinucleotide phosphate diaphorase. Brain Res. Bull. 62, 107-115.

Gomes, M. Z., Raisman-Vozari, R. and Del Bel, E. A. (2008). A nitric oxide synthase inhibitor decreases 6-hydroxydopamine effects on tyrosine hydroxylase and neuronal nitric oxide synthase in the rat nigrostriatal pathway. Brain Res. 1203, 160-169.

Guix, F. X., Uribesalgo, I., Coma, M., and Munoz, F. J. (2005). The physiology and pathophysiology of nitric oxide in the brain. Prog. Neurobiol. 76, 126-152.

Henry, B., Crossman, A. R., and Brotchie, J. M. (1998). Characterization of enhanced behavioral responses to L-DOPA following repeated administration in the 6-OHDA-lesioned rat model of Parkinson's disease. Exp. Neurol. 151, 334-342.

Hunot, S., Boissière, F., Faucheux, B., Brugg, B., Mouatt-Prigent, A., Agid, Y., and Hirsch, E. (1996). Nitric oxide synthase and neuronal vulnerability in Parkinson's disease. Neuroscience 72, 355-363.

Iancu, R., Mohapel, P., Brundin, P., and Paul, G. (2005). Behavioral characterization of a unilateral 6-OHDA-lesion model of Parkinson's disease in mice. Behav. Brain Res. 162, 1-10.

Itokawa, K., Ohkuma, A., Araki, N., Tamura, N., and Shimazu, K. (2006). Effect of L-DOPA on nitric oxide production in striatum of freely mobile mice. Neurosci. Lett. 402, 142-144

Jenner, P. (2008). Molecular mechanisms of L-DOPA-induced dyskinesia. Nat Rev. Neurosci. 9, 665-677.

Kavya, R., Saluja, R., Singh, S., and Dikshit, M. (2008). Nitric oxide synthase regulation and diversity: implications in Parkinson's disease. Nitric Oxide 15,280-294.

Kawaguchi, Y. (1997). Neostriatal cell subtypes and their functional roles. Neurosci. Res. 27, 1-8.

Konitsiotis, S., and Tsironis, C. (2006). Levodopa-induced dyskinesia and rotational behavior in hemiparkinsonian rats: independent features or components of the same phenomenon? Behav. Brain Res. 170, 337-341.

Kubota, Y., Mikawa, S., and Kawaguchi, Y. (1993). NeostriatalGABAergicinterneurones contain NOS, calretinin or parvalbumin. Neuroreport 5, 205-208.

Lane, E. L., Cheetham, S. C., and Jenner, P. (2006). Does contraversive circling in the 6-OHDA-lesioned rat indicate an ability to induce motor complications as well as therapeutic effects in Parkinson's disease? Exp. Neurol. 197, 284-290.

Lane, E. L., Soulet, D., Vercammen, L., Cenci, M. A., and Brundin, P. (2008). Neuroinflammation in the generation of post-transplantation dyskinesia in Parkinson's disease. Neurobiol. Dis. 32, 220-228.

Lundblad, M., Andersson, M., Winkler, C., Kirik, D., Wierup, N., and Cenci, M. (2002). Pharmacological validation of behavioural measures of akinesia and dyskinesia in a rat model of Parkinson's disease. Eur. J. Neurosci.15, 120-132.

Marsden, C. D., and Parkes, J. D. (1977). Success and problems of long-term levodopa therapy in Parkinson's disease. Lancet 1, 345-349.

Miller, R., and Beninger, R. J. (1991). On the interpretation of asymmetries of posture and locomotion produced with dopamine agonists in animals with unilateral depletion of striatal dopamine. Prog. Neurobiol. 36, 229-256.

Monville, C., Torres, E. M., and Dunnett, S. B. (2006). Comparison of incremental and accelerating protocols of 
the rotarod test for the assessment of motor deficits in the 6-OHDA model. J. Neurosci. Methods 158, 219-223.

Morello, M., Reiner, A., Sancesario, G., Karle, E. J., and Bernardi, G. (1997). Ultrastructural study of nitric oxide synthase-containing striatal neurons and their relationship with parvalbumin-containing neurons in rats. Brain Res. 776, 30-39.

Mura, A., Mintz, M., and Feldon, J. (2002). Behavioral and anatomical effects of long-term L-dihydroxyphenylalanine (L-DOPA) administration in rats with unilateral lesions of the nigrostriatal system. Exp. Neurol. 177, 252-264.

Novaretti, N., Padovan-Neto, F. E., Tumas, V., Da-Silva, C. A., and Del Bel, E. A. (2010). Lack of tolerance for the antidyskinetic effects of 7-nitroindazole, a neuronal nitric oxide synthase inhibitor, in rats. Braz. J. Med. Biol. Res. 43, 1047-1053.

Olsson, M., Nikkhah, G., Bentlage, C., and Björklund,A. (1995). Forelimb akinesia in the rat Parkinson model: differential effects of dopamine agonists and nigral transplants as assessed by a new stepping test. J. Neurosci. 15, 3863-3875.

Padovan-Neto, F. E., Echeverry, M. B., Tumas, V., and Del-Bel, E. A. (2009). Nitric oxide synthase inhibition attenuates L-DOPA-induced dyskinesias in a rodent model of Parkinson's disease. Neuroscience 159, 927-935.

Papa, S. M., Engber, T. M., Kask, A. M., and Chase, T. N. (1994). Motor fluctuations in levodopa treated Parkinsonian rats: relation to lesion extent and treatment duration. Brain Res. 662, 69-74.

Pavón, N., Martín, A., Mendialdua, A., and Moratalla, R. (2006). ERK phosphorylation and FosB expression are associated with L-DOPA-induced dyskinesia in hemiparkinsonian mice. Biol. Psychiatry 59, 64-74.

Paxinos, G., and Watson, C. (1998). The Rat Brain in Stereotaxic Coordinates. New York: Academic Press.

Ponzoni, S., Guimarães, F. S., Del Bel, E. A., and Garcia-Cairasco, N. (2000).
Behavioral effects of intra-nigral microinjections of manganese chloride: interaction with nitric oxide. Prog. Neuropsychopharmacol. Biol. Psychiatry 24, 307-325.

Przedborski, S., Jackson-Lewis, V., Yokoyama, R., Shibata, T., Dawson, V. L., and Dawson, T. M. (1996). Role of neuronal nitric oxide in 1-methyl4-phenyl-1,2,3,6-tetrahydropyridine (MPTP)-induced dopaminergic neurotoxicity. Proc. Natl. Acad. Sci. U.S.A. 93, 4565-4571.

Qureshi, G. A., Baig, S., Bednar, I., Sodersten, P., Forsberg, G., and Siden, A. (1995). Increased cerebrospinal fluid concentration of nitrite in Parkinson's disease. Neuroreport 6, 1642-1644.

Sancesario, G., Giorgi, M., D’angelo, V., Modica, A., Martorana, A., Morello, M., Bengtson, C. P., and Bernardi, G. (2004). Down-regulation of nitrergic transmission in the rat striatum after chronic nigrostriataldeafferentation. Eur. J. Neurosci. 20, 989-1000.

Sanchez, J. J., Abreu, P., and Gonzalez, M. C. (2002). Sodium nitroprusside stimulates L-DOPA release from striatal tissue through nitric oxide and cGMP. Eur. J. Pharmacol. 438, 79-83.

Santini, E., Alcacer, C., Cacciatore, S., Heiman, M., Hervé, D., Greengard, P., Girault, J. A., Valjent, E., and Fisone, G. (2009). L-DOPA activates ERK signaling and phosphorylates histone $\mathrm{H} 3$ in the striatonigral medium spiny neurons of hemiparkinsonian mice. J. Neurochem. 108, 621-633.

Schwarting, R. K., Bonatz,A.E., Carey, R.J., and Huston, J. P. (1991). Relationships between indices of behavioral asymmetries and neurochemical changes following mesencephalic 6-hydroxydopamine injections. Brain Res. 554, 46-55.

Schwarting, R. K., and Huston, J. P. (1996). Unilateral 6-OHDA lesions of meso-striatal dopamine neurons and their physiological sequelae. Prog Neurobiol. 49, 215-266.

Sullivan, R. M., Fraser, A., and Szechtman, H. (1994). Asymmetrical orientation to edges of an openfield: modulation by striatal dopamine and relationship to motor asymmetries in the rat. Brain Res. 637, 114-118.

Tepper, J. M., and Bolam, J. P. (2004). Functional diversity and specificity of neostriatal interneurons. Curr. Opin. Neurobiol. 14, 685-692.

Trabace, L., Cassano, T., Tucci, P., Steardo, L., Kendrick, K. M., and Cuomo, V. (2004). The effects of nitric oxide on striatal serotoninergic transmission involve multiple targets: an in vivo microdialysis study in the awake rat. Brain Res. 2008, 293-298.

Tuite, P., and Riss, J. (2003). Recent developments in the pharmacological treatment of Parkinson's disease. Expert. Opin. Investig. Drugs 12, 1335-1352.

Ungerstedt, U., and Arbuthnott, G. W. (1970). Quantitative recording of rotational behavior in rats after 6-hydroxydopamine lesions of thenigrostriatal dopamine system. Brain Res. 24, 485-493.

Vandesompele, J., De Preter, K., Pattyn, F., Poppe, B., Van Roy, N., De Paepe, A., and Speleman, F. (2002). Accurate normalization of real-time quantitative RT-PCR data by geometric averaging of multiple internal control genes. Genome Biol. 3, research0034.1-research0034.11.

West, A. R., and Grace, A. A. (2002). Opposite influences of endogenous dopamine D1 and D2 receptor activation on activity states and electrophysiological properties of striatal neurons: studies combining in vivo intracellular recordings and reverse microdialysis. J. Neurosci. 22, 294-304.

West, A. R., and Grace, A. A. (2004). The nitric oxide-guanylylcyclase signaling pathway modulates membrane activity states and electrophysiological properties of striatal medium spiny neurons recorded in vivo. J. Neurosci. 24, 1924-1935.

Winkler, C., Kirik, D., Björklund, A., and Cenci, M.A. (2002). L-DOPA-induced dyskinesia in the intrastriatal 6-OHDA model of Parkinson's disease: relation to motor and cellular parameters of nigrostriatal function. Neurobiol. Dis. 10, 165-186.

Zetterström, T., Herrera-Marschitz, M., and Ungerstedt, U. (1986). Simultaneous measurement of dopamine release and rotational behaviour in 6-hydroxydopamine denervated rats using intracerebral dialysis. Brain Res. 376, 1-7.

Zhang, J., Graham, D. G., Montine, T. J., and Ho, Y. S. (2000). Enhanced $\mathrm{N}$-methyl-4-phenyl-1,2,3,6tetrahydropyridine toxicity in mice deficient in CuZn-superoxide dismutase or glutathione peroxidase. J. Neuropathol. Exp. Neurol. 59, 53-61.

Conflict of Interest Statement: The authors declare that the research was conducted in the absence of any commercial or financial relationships that could be construed as a potential conflict of interest.

Received: 23 February 2011; accepted: 23 May 2011; published online: 10 June 2011.

Citation: Padovan-Neto FE, Echeverry $M B$, Chiavegatto S and Del-Bel E (2011) Nitric oxide synthase inhibitor improves de novo and long-term L-DOPA-induced dyskinesia in hemiparkinsonian rats. Front. Syst. Neurosci. 5:40. doi: 10.3389/ fnsys.2011.00040

Copyright (C) 2011 Padovan-Neto, Echeverry, Chiavegatto and Del-Bel. This is an open-access article subject to a nonexclusive license between the authors and Frontiers Media SA, which permits use, distribution and reproduction in other forums, provided the original authors and source are credited and other Frontiers conditions are complied with. 